\title{
Measures Adopted to Reduce Drug and Substance Abuse in Public Secondary Schools in Kenya
}

\author{
Richard Rono $^{1}$ Isaac Njuguna Kimengi ${ }^{2} \quad$ Felicity Wanjiru Githinji ${ }^{3}$ \\ Dept. of Educational Foundations, Moi University \\ P.O. Box 3900-30100, ELDORET, Kenya
}

\begin{abstract}
The use of drugs is a major societal concern, and schools are considered a privileged space for the development of prevention measures and health promotion. It is possible, and desirable, for schools to be concerned with drug demand reduction, drug supply reduction and mitigating the health and social consequences of drug use with major focus on demand reduction. The purpose of this study was to establish measures to be adopted to reduce drug and substance abuse in public secondary schools in Kenya. The research was based on social learning theory. The research was conducted in Nandi County schools in Kenya. Twenty four randomly selected schools out of 235 county schools were engaged in the study. A sample size of 1292 respondents was obtained using purposive and simple random sampling techniques. The participants included Deputy Principals, Counselors, and teachers teaching Life Skills subject, students and Focus Group Discussions. The data instruments utilized included questionnaires and structured interviews. The data collected was analyzed using descriptive statistics, frequency, tables, graphs, pie charts and percentages. The results of this study revealed that drug abuse in schools was a challenge that needed to be addressed by all stake holders in education. Outsiders were found to be clandestinely selling drugs to students during festivities such as music and games. Teachers and school security officers in most schools did not bother to check on student luggage on arrival during opening and midterms which became an easy leeway of getting drugs into schools. The research findings would be useful to schools, parents, research practitioners and school administration.
\end{abstract}

Keywords: Challenges, teachers, learners, social net-working, Drugs and Substance Abuse.

DOI: $10.7176 / \mathrm{JEP} / 10-23-14$

Publication date: August $31^{\text {st }} 2019$

\subsection{Introduction}

The use of drugs is a major societal concern, and schools are considered a privileged space for the development of prevention and health promotion. According to Gateway Foundation Life Saving and Treatment 2019, more than 7 million people, youth included suffer from illicit drug use disorder and one in four deaths can be attributed to alcohol, tobacco, and illicit or prescription drug use. It is possible, and desirable, for schools to be concerned with drug demand reduction, drug supply reduction and mitigating the health and social consequences of drug use, with the major focus on demand reduction. It is the primary role of the school to teach skills, to impart knowledge and to establish a sound values base in relation to health and drug use.

The well-established pattern of onset and progression of substance use and abuse during adolescence has led to the development of a variety of prevention initiatives for children and adolescents. According to Sarah L. (2018), there are four ways to preventing alcohol and drug abuse in teens namely: 1) communicate. Talk openly with teens about what they are and are doing is essential. 2) Set boundaries. Making your expectations known early is important when setting boundaries with your teens. It helps them know the consequences. 3) Lead by example. If you are heavily dependent on alcohol or if it's a big factor in your social life, you could be setting a detrimental example. 4) be available and ensure you direct them toward understanding the negative effects of drug abuse on their lives.

Prevention efforts must address all stages of life; from infancy to adulthood, prevention can reduce both the use and abuse of alcohol and other drugs (CSAP, 1983). According to NIDA (2017), preventing teenage drinking and drug abuse can limit the amount of negative consequences facing teens and society as a whole.

Research carried out by Rooner, Streke, \& Marshall (2003), suggests that the following elements are essential to developing and implementing effective school-based alcohol prevention intervention: Interventions are theoryis driven with a particular focus on the social - influence model, which emphasize helping students identify and resist social influence for instance by peers and media. The interventions should address social norms around alcohol use, reinforcing that alcohol use is not common or acceptable among the youth.

The interventions use the same aged-students, that is, peer leaders to facilitate delivery of the program. The interventions are conducted across multiple sessions and multiple years to ensure that adequate 'dose' of prevention, is received by students and schools. The interventions provide adequate training and support for program facilitation for teachers and students. The interventions integrate additional components to connect other segments of the community for example parents to the program. A practical program namely "Say No" to DSA was set up in the U.S in the 1970s. It is founded on the tenets of social inoculation theory (Evans, 1983). It assumes 
that adolescents' decision does not drink or ingest drugs is grounded in their ability to refuse peer pressure. Inculcating resistance skills is believed to "inoculate" young people from these pressures much as vaccines inoculate people from polio or other contagious diseases.

\subsection{Purpose of the Study}

The purpose of this study was to establish measures to be adopted to reduce drug and substance abuse in public secondary schools.

\subsection{Objectives of the Study}

The objectives of the study were to establish:

1. Demographic characteristics of the respondents.

2. Students' responses on measures to be adopted to reduce drug and substance abuse.

3. Guidance and counseling teachers' responses on measures to be adopted to reduce drug and substance abuse.

4. Focus Group Discussions responses on measures to be adopted to reduce drug and substance abuse.

5. Teachers taking life skills subject responses on measures to be adopted to reduce drug and substance abuse.

\subsection{Research Methodology}

The objective of the inquiry in the study was to find out students, Guidance and Counseling teachers and teachers taking Life Skills subject responses on measures to be adopted to reduce drug and substance abuse in public secondary school. A descriptive research design was used. Questionnaires were administered to 1002 students and 24 four teachers teaching life skills. Semi structured interview schedules were used with 24 Deputy Principals, 24 Counselors and 120 Focus Discussion Groups. Purposive and random sampling techniques were used to select the respondents in Nandi county schools. The study presented the results from the questionnaires in frequency tables showing frequencies and percentages on the opinions of the respondents. The study results from the interview were organized, coded and discussed based on emerging issues on drug and substance abuse.

\subsection{Discussions of Study Findings}

\subsubsection{Demographic characteristics of the respondents}

The researcher determined the gender, age, educational level, duration of work as well as students family background to determine the nature of the respondents.

\section{Gender}

The gender of the respondents is presented in table 1

Table 1: Gender Distributions of the Respondents

\begin{tabular}{llll}
\hline Students & Gender & & \\
\hline & Male & Female & Total \\
Frequency & 509 & 493 & 1002 \\
Percent & $50.8 \%$ & $49.2 \%$ & $100 \%$ \\
\hline
\end{tabular}

\section{Source: Field Data (2017)}

Based on table 1, the results indicated that the proportion of male students sampled was $509(50.8 \%)$ which was higher than that of the females 493(49.2\%) among the schools.

\subsubsection{Category of Schools}

Table 2 established that boys were on the lead in all categories of mixed schools. In SCMD, boys were 500 (62\%) while girls were 300 (38\%). In CMB, boys were 233 (73\%) and girls were 87 (27\%), while, in CMD, boys were $400(63 \%)$ and girls were $240(37 \%)$. The findings of the study were supported by research findings by Zarman (2015) among students in different universities in Pakistan. The findings revealed that the percentage of drug abuse was greater in males as compared to females.

Table 2: Category of Schools

\begin{tabular}{|c|c|c|c|}
\hline & Category of Schools & & \\
\hline Response & SCMD & CMB & CMD \\
\hline General distribution & Boys $500(62 \%)$ & Boys $233(73 \%)$ & Boys $400(63 \%)$ \\
\hline DSA in mixed schools & Girls $300(38 \%)$ & Girls 87 (27\%) & Girls $94(\%)$ \\
\hline
\end{tabular}

Source: Field Data (2017)

1.4.3 Status of the School

From table 3, the findings show that the expected number of students from each class to fill and return the forms were 16 from 69 streams as clarified in table 3 giving a total of 1104 but only 1002 managed to fill and return the forms. The return rate stood at $1002(90.7 \%)$ as shown in table 3 as was affected in form one to form four in terms of expected and the actual count. 
Table 3: Class/Form of the Respondents in Public Secondary Schools

\begin{tabular}{lll}
\hline Class/Form & Frequency & Percentage (\%) \\
\hline One & 252 & $91.3 \%$ \\
Two & 248 & $89.9 \%$ \\
Three & 250 & $90.6 \%$ \\
Four & 248 & $89.9 \%$ \\
Total & 1002 & $90.7 \%$ \\
\hline
\end{tabular}

The study sought to establish measures to be adopted to reduce drug and substance abuse in public secondary schools. The study results are as illustrated in table 4

Students Responses on measures to be adopted to reduce Drug and Substance Abuse

\begin{tabular}{|c|c|c|c|c|c|c|c|c|}
\hline & & SD & D & $\mathbf{U}$ & $\mathbf{A}$ & SA & Total & Mean \\
\hline \multirow{2}{*}{$\begin{array}{l}\text { Training of peer educators, teachings } \\
\text { on substance and use of professional } \\
\text { counselors }\end{array}$} & $\mathrm{F}$ & 0 & 26 & 10 & 723 & 2433 & 1002 & 4.14 \\
\hline & $\%$ & 0 & 2.9 & 1.1 & 74.6 & 21.4 & 100 & 82.8 \\
\hline \multirow{2}{*}{$\begin{array}{l}\text { Keep the channels of communication } \\
\text { open and fostering an environment that } \\
\text { encourages a commitment to learning }\end{array}$} & $\mathrm{F}$ & 0 & 20 & 4 & 648 & 331 & 1002 & 4.26 \\
\hline & $\%$ & 0 & 2.2 & 0.4 & 66.3 & 31.2 & 100 & 85.2 \\
\hline \multirow{2}{*}{$\begin{array}{l}\text { Formation of clubs and encouragement } \\
\text { of a constructive use of time }\end{array}$} & $\mathrm{F}$ & 0 & 20 & 6 & 680 & 295 & 1002 & 4.22 \\
\hline & $\%$ & 0 & 2.2 & 0.7 & 69.9 & 27.2 & 100 & 84.4 \\
\hline \multirow{2}{*}{$\begin{array}{l}\text { Set clear classroom boundaries with } \\
\text { clear rules and consequences and }\end{array}$} & $\mathrm{F}$ & 0 & 20 & 16 & 671 & 295 & 1002 & 4.21 \\
\hline & $\%$ & 0 & 2.2 & 1.8 & 68.8 & 27.2 & 100 & 84.2 \\
\hline
\end{tabular}
encouraging participation in extracurricular activities

\section{Key: SD=Strongly Agree, $\mathrm{D}=$ Disagree, $\mathrm{U}=$ Undecided, A=Agree, $\mathrm{SA}=$ Strongly Agree, \%=Percentage,} $\mathrm{F}=$ frequency

The study results revealed that $648(74.6 \%)$ of the responses were of the agreed that training of peer educators, teachings on drug and substance abuse and use of professional counselors had to be put in place. This concurs with Peer education-Wikipedia (2019) that peer educators can be effective role models for adolescents by promoting healthy behavior, helping to create and reinforce social norms that support safer behaviors both inside and outside the classroom. $680(66.3 \%)$ of the respondents were of the view that keeping the channels of communication open and fostering an environment that encourages a commitment to learning was of paramount importance in the curbing DSA in schools, $680(69.9 \%)$ were of the opinion that formation of clubs and encouragement of a constructive use of time had to be initiated for the good of the students to avoid drug and substance abuse, while $671(68.8 \%)$ of the responses were of the opinion that set clear classroom boundaries with clear rules and consequences and encouraging participation in extra-curricular activities was vital in eradicating the menace of DSA in schools.

All teachers of guidance and counseling $24(100 \%)$ were asked to give suggestions on how to reduce DSA in secondary schools, they gave the following responses that there was need to strengthen Guidance and Counseling in schools through the provision offices for the teacher counselors, that open forums for students should be facilitated by schools and be held regularly to discuss on the dangers of illicit drugs in secondary schools and come with lasting solutions by students themselves, that specialists in drug abuse should invited by the schools so as to address DSA menace among students in good time and save the majority of students before they fall victims to irreversible drug abuse. Teachers handling Guidance and Counseling regularly be in-serviced on techniques of handling the emerging issues on DSA. The Ministry of Education should provide infra-structure finance to enable schools install CCTV Cameras so as to enable school administration monitor what goes on in school compounds. This assertion is in agreement with Himanee C. (2018), that Counselors will be able to provide guidance and counseling services to students if their needs are addressed. Guidance and counseling are very much required for school/college going students to identify their strengths and weaknesses and at the same time work on their strengths and area of interest to do wonders in future.

All the 120(100\%) Focused Discussion Group sampled for this study availed themselves in all categories of schools. When they were asked if they had used drugs apart from medical purpose in their discussion, 3(60\%) students in NBB confessed that they had used drugs for none medical purpose and, 2(40\%) had not. In SCMD $12(40 \%)$ responded that they used drugs for non-medical purpose while $18(60 \%)$ had not. In CBB all $41(90 \%)$ of students in this category accepted having used drugs for none medical purpose while $4(10 \%)$ students had not used. In SCGB 15(60\%) had used while 10(40\%) had not. In CMB 4(80\%) had used drugs and only $1(20 \%)$ had not. It was also found that 3(60\%) students in CMD had utilized drugs and only 2(40\%) had not. Finally, in CBG 3(60\%) as well had used drug apart from medical and 2(40\%) had not. From the above analysis drug and substance abuse was real and widespread in all categories of schools for the obvious fact that greater percentage of students had 
abused drugs and those that had not used were at a risk of getting influenced into drug abuse. The projection pinpointed that the number of drug abusers was on increase day in- day out in all the schools.

Students in their open and free discussions were able to reveal those that introduced them to drug abuse. All students from all categories of schools were able to identify them as friends and parents who drink and smoke freely in their homes. $24(20 \%)$ of student also identified a section of teachers contributed to their drug abuse habits in schools especially in smoking of cigarettes and drinking of alcohol which led them to the abuse of other related dangerous drugs like bhang, mandrax, cocaine among others. Students found teachers to be their role models in this vice.

During Focused Group Discussions, it was found that SCMDs were on the lead in DSA as $784(49 \%)$ of students abused drugs and $816(51 \%)$ abstained from drug abuse. It was then followed by CMB recording a figure of $288(45 \%)$ of students that engaged in drug abuse and $352(55 \%)$ did not abuse drugs. In third place was CMD with 282(44\%) abusing drugs and 358(56\%) were found to be free from drug menace. In fourth place was the CBB with 2004(40\%) students involved in DSA and 2976(60\%) kept off drug abuse. In the fifth place was CBG with $187(39 \%)$ students consuming drugs and 293(61\%) refrained from drug and substance abuse in their schools. In sixth position was NBB with 355(37\%) students found involved in DSA and 605(63\%) students kept off from the vice. Finally, in SCGB 432(30\%) of students were found to be consuming prohibited drugs and $1008(70 \%)$ did not participate in DSA.

They also revealed that students had contacts with outsiders who secretly supplied the drugs at specific points on regular basis. They further revealed that drugs came to usage through creative and tactical ways employed by ranging from adding another layer of timber on desk in classes to a layer of iron sheet for their boxes in dormitories.

The FGDs revealed that they connected with other students during school funkies such as clubs and symposiums and exchanged phone contacts. It was during this moment that they came with weed and tobacco. They claimed that since students did not come from their school, the visiting teams were not frisked. They sneaked anything that the host students needed. They revealed that they hid the drugs in their inner wears.

From students, in their deliberations on who was responsible for drug coordination and distribution, the student FDGs in all categories of schools identified the watchmen, cooks and senior students as the main perpetrators. In as far as the presence of a school rule addressing drug abuse in schools the students agreed there was such rule but toothless since students continued abusing drugs despite its presence.

This study sought to establish where students took drugs in their schools. FDGs in their thorough discussions on DSA they were able to identify places where students ingest drugs in such places as toilets; along school fences; dormitories; in school farms and even class rooms even in the presence of teachers as learning continued. They placed tabled or sweet like drugs for instance kuber in between their cheeks and gums, and continued chewing them unnoticed by their teachers. In some instances students got into blackouts and were mistaken for having been struck diseases such as malaria or affected by abnormal conditions of epilepsy, only to be diagnosed and found to be under the influence drug abuse, a monster in waiting to devour the entire institutions of learning if no measures were taken to combat and apprehend it the soonest time possible.

The study sought to establish student hide-outs for taking drugs in schools. The FGDs in their exhaustive engagements, from all categories of schools were able to pin point the hide-outs of drug abuse among students to be: their mattress; along the edges of school fences; roofs of school buildings; toilets and their inner wears so as to avoid detection from teachers. The FGDs were able to identify time for taking drugs as at night, lunch break, in the morning preps and games time. It was also established that, students in their scheme to avoid detection from teachers as they take drugs in schools, they group themselves and either go under a tree within the school compound or in open fields and pretend to be involved group discussions as they took drugs.

The study sought find out if students were briefed on danger of DSA in schools by their teachers, they responded that at least, once in a while the teachers and the school administration cautioned them on the dangers of ingesting harmful drugs for the sake of pleasure and escapism from idleness and pressure of work while at school. When students were asked if their schools organize for students open forum to air their views on DSA in their respective schools 5 (71\%) categories of schools namely: NBB, CBB, SCGB, CBG, and CMB agreed that they were briefed by their teachers, while 2(29\%)-SCMD and CMD said such information was rare in their schools. This was attributed to the fact that these were day schools and students did not pose much problems to teachers since they went to their homes in the evening and reported back to schools in the morning and were out of school over the weekends unlike in boarding schools where they are in school full time hence causing a lot of problems due to confinement.

NBB, CBB, SCGB, CMB and CBG agreed that they held open forums to discuss the impact of drugs and substance abuse in their schools. While SCMD and CMD never held such forums. In this case it was clear that boarding schools hold forums while day schools did not have them. This therefore called for thorough sensitization in day schools on the importance of holding open forums for the reduction of DSA in those schools. From the analysis in table 4.23 , it was realized that the two categories of day schools were on the lead in drug and substance abuse. SCMD led with $49 \%$ of drug abusers followed by SCMD with $44 \%$. The reason being that they never 
addressed the problem of DSA in open forums in their schools.

The study sought to establish if there was any school rule that addressed DSA in schools. All students from all categories schools responded that there was a rule that there was a rule that addressed the drug menace as shown in table 4.37 but was not followed.

During deliberations on suggestions on methods that can be used to reduce DSA in schools, the student FDGs in all categories of schools came up with the following suggestions as reflected in table 4.38:That peer counseling should be encouraged and supported in all schools. The FDGs found it relevant since it was students based arrangement and they know who was the drug addict or abuser, hence they can easily find remedy to the affected students. Regular brisking of students be carried out in schools so that the culprits netted before they spread harmful drugs to the rest of the students of the innocent students, that all schools should conduct open forums with students. The FDGs found it practical since students will air their grievances in good time hence build up pressure that could lead to frustrations among students that could redirect them to drug abuse as a route to get out their problems is minimized. Those CCTV cameras be installed in all schools to enable school administrations monitor all the happenings in the schools including drug abuse among students.

According to teachers taking skills in national boys boarding, form four are the greatest abusers of the drugs. In sub-county mixed day schools, form twos were identified as the main drug abusers. In county boarding boys, form two were found to be the leading drivers in drug abuse in these schools while in sub-county girls boarding and county mixed boarding form three were found to be the main culprits of drug abuse. In county mixed day, form four class were the leading drug abusers. Finally, in county boarding girls, form three was identified as the main drug abusers in those schools. Frequency from the analysis showed that form three and four classes are at the forefront in drug abuse in most of the categories of schools.

For the case of mixed schools it was found that more boys were involved in drug abuse than girls. Generally speaking, the drugs abused are: alcohol, bhang, cigarette and kuber. This was in agreement with what the deputy principals reported during their interviews. It was also found that in most of the county boarding school and national schools, the majority of drug abusers came from the urban areas, while in sub-county schools came from rural areas since majority of them came from the immediate environment. From the response of all the 24 teachers of all categories of schools, they were able to identify reasons why students take drugs in their schools as taking them for fun, excessive pocket money held by students, poor discipline in schools, rebellion against staff and school administration, curiosity, frustrations due to pressure from school work like assignments, examinations and being compelled to rise from bed quite early in the morning for preps and school duties among others. Other reasons why student's especially male students take drugs are to get courage and confidence to talk to girls. From this scenario it was found that substance abuse was rife during inter-school visits. Another reason given for students' ingestion of drugs was that they hoped it would increase or boost their academic performance because pressure from teachers, parents and the society was too demanding as they expected them to do well in school.

It was also found that drug abuse among students is almost an everyday affair and the key perpetrators of drug abuse in most of schools are those students admitted from other schools in various forms as from form two to four. When teachers handling Life Skills subject were asked about the social net-workings that the students use to infiltrate drugs into their schools all of them were able to identify mobile phones as the gadgets that students use to connect with drug peddlers. It was a big concern to teachers of Life Skills that mobile phones owned by students should be confiscated and destroyed and students found with the gadgets be severely punished so as to deter others from engaging in such acts. They as well identified a section of school workers such as grounds men and cooks in their schools as responsible for drug proliferation in their schools.

In national and county schools, the teachers of life skills reported that they have open forums to discuss on the effects of drug abuse every fortnight while in most of the sub-county schools it was a rare activity. Despite the fact that these forums are there in both national and county schools, they have not yielded much positive results due to uprisings and riots witnessed in schools almost on daily basis and it were attributed to drug abuse among students. It was found that in most schools, invitation of guest speakers on drug abuse was found to be a rare phenomenon due to financial constraints. It was only found that in national boarding boys and some few county schools were able to afford the invitation of drug abuse experts.

When life skills teachers were asked if they attended workshops of life skills, their response was negative. They reported that they have never had such a thing in their teaching of life skills subjects.

Life skills teachers rated poorly the content of drug abuse in the syllabus in all categories. They found it to be too inadequate to make any impact on students' behavior as far as drug abuse is concerned. They further said that in some subjects there is no content of drug abuse. When teachers of life skills teachers from all these categories were asked to give their opinions on how to eradicate drug abuse in schools, they responded that offices of guidance and counseling in schools should be manned by guidance and counselor professionals. Teachers should develop and foster positive relationship with non-teaching staff in their schools, students, the neighborhoods in schools and families of the students. Teachers should be involved in coming up with the practices and development of knowledge and skills required for the management of behavior change among students. Installation of CCTV 
cameras in schools to help monitor day-in -day-out activities among all players in school community and that the ministry should finance the guidance and counseling department so that the right materials and qualified speakers are hired in schools to sensitize students on the dangers of DSA. When teachers of guidance and counseling were asked where the students get the drugs that they abuse in their schools, most of them said that students got them from bodaboda men, other students, hawkers, kiosks, nearby shops, surrounding community, some school workers among others.

When teachers of life skills were asked what the ministry should do to eradicate DSA in schools, most of them responded that syllabus content be increased and be made relevant to capture the menace of DSA in secondary schools. Teacher should be trained professionally on the subject of life skills and professional Guidance and counseling personnel to be posted to schools. CCTV cameras to be installed in every school to help in arresting those students involved in DSA. The ministry should introduce a program that inducts teachers to be true models to students by not coming to school while drunk or under any influence of a drug that is, teachers to exercise selfdiscipline and refrain from acts that tempt students to go for drug abuse. The ministry to come up with strong personnel in every county that go round to sensitize students on the dangers of drug abuse on regular basis and that the ministry to introduce stringent measures to deal with drug dealers, traffickers and whoever is found engaging in selling drugs to students. The ministry should involve teachers in the formulation of policy to curb drug abuse among students in schools. Rehabilitation centers solely for students should be introduced in every county to help in rehabilitating the affected students. The schools should ensure that students do not come with mobile phones to school because these are the gadgets they use in coordinating the in-flow of drugs into the schools.

The findings from the study established that, though $50 \%$ of schools in urban setting had clubs that were meant to address the drug abuse in their schools, it achieved less than expected due to the fact that teachers did not take them seriously and they were only left to students to decide on what to address during clubs time. The question on whether the introduction of drug abuse in the syllabus had made any impact on the abuse of drugs the study findings established there was no effect. Instead of drug abuse decreasing, it has been heavily on the increase in all categories of schools.

When the respondents were asked to suggest other methods that can be used to eradicate DSA in all categories of school the findings of the study revealed that schools are in dire need of eradicating drugs from their schools and gave the following suggestions:

The students recommended that students in all schools should not be allowed to come to school with mobile phones since this are the gadgets they utilize to coordinate drug in-flow into the schools. They said a strict rule should be formulated on student mobile phones so as to deter them from bringing and using them in schools.

The students suggested that professional teacher counselors be posted to schools to arrest the abuse of drugs by students. They felt that the teachers handling the subject were not prepared right from training institutions to go and teach Life Skills subject. In fact $441(40 \%)$ of students revealed that some teachers confess to students that they were not professionally trained to handle Life Skills subject and that they were forced by the school administration to teach the subject.

The students felt that Life Skills subject should be made examinable by the Kenya National Examination Council so that both teachers and students give it the seriousness it deserves for the purpose of changing student lives by stopping DSA. The students also proposed that CCTV cameras be installed in all schools in Kenya so that students are monitored effectively from time to time for their own good and bring to an end the abuse of drugs in schools.

Students suggested that rehabilitation centers for students alone be established to handle extreme cases of student drug abuse for the purpose of effective management of the affected students. They were of the opinion that students alone are freer to express their feelings and problems when they are with their age mate colleagues.

Students suggested that strong trained peer counselors be established in schools. They felt that this could help in monitoring the wayward students and save them in good time before they wipe themselves out. $50 \%$ of students were of the opinion that all schools should be turned into day schools so that each parent and the immediate community are able to monitor the movement and activities of their children.

\subsection{Conclusions}

It was established that drug and substance abuse among students is an everyday affair in Kenyan secondary schools and has taken unprecedented level and escalation and is on a sharp rise too. It was noted that there are intermediate connectors in form of school worker, teachers and outsiders who aggravate drug and substance abuse in secondary schools. This therefore calls for the need for all stakeholders -school administrators, teachers ,Boards of Management, students, parents, the Ministry of Education, policy makers and security of the nation to come together and chat a way forward in order to bring drug and substance abuse to manageable level. All is not lost.There is still hope of saving the situation from other dilapidation due to abuse of drugs among students if urgent corrective measures are initiated with commitment it deserves for the safety of the nation now and future. 


\subsection{Recommendations}

1. Strong trained peer counselors be established in schools.

2. Professional teacher counselors be posted to schools.

3. Students should not come to school with mobile phones.

4. Rehabilitation centers be established to cater for the affected students.

\section{References}

Gateway Foundation (2019). Effects of Drug Abuse and Addiction https://www.gatewayfoundatio.org NIDA. (2017). The importance of Teen Substance Abuse Prevention https://www addiction center.com Sarah, L. (2018). 4 ways to prevent alcohol and drug abuse in your teens. https://psychcentral.com NIDA (2017). Prevention of teenage drinking and drug abuse

Rooner, S. \& Marshall (2003). Developing and implementing programs on drug prevention Evans, R.I. (1983). Social inoculation Strategy to deter drug abuse among the teens

CSAP (1983). A Handbook of drug abuse prevention

Himanee C. (2018). Importance of Guidance and Counseling for school/College Going Students Peer Education-Wikipedia (2019). https://en.m.wikipedia.org Zarman (2015). Drug abuse affecting the university students 